\title{
Jay Grosfeld, MD, FACS, FAAP, FRCS, FRCPS, FRSH (1935-2016)
}

\author{
Martin Kaefer $^{1}$
}

Published online: 13 July 2017

(c) Société Internationale de Chirurgie 2017

Dr. Jay Lazar Grosfeld was born in New York City on May 30, 1935. He attended undergraduate school at the Washington Square College at New York University (NYU) where he received a B.S. in Biology and a B.A. in History, graduating Phi Beta Kappa, Cum Laude. He attended medical school at the New York University School of Medicine, and then trained in General Surgery at NYU and Bellevue Hospitals from 1961 to 1966. After serving two years as a Captain in the US Army Medical Corps and receiving the Army Commendation Medal for Distinguished Service, he trained in Pediatric Surgery at the Nationwide Children's Hospital at Ohio State University. He returned to NYU as Assistant Professor of Surgery in 1970. In 1972, Dr. Grosfeld was appointed Professor and Director of Pediatric Surgery at Indiana University and the first Surgeon-in-Chief of the Riley Children's Hospital in Indianapolis, Indiana. He pioneered the development of pediatric surgery in the state and set the standard for the surgical care of infants and children. In 1985, he was appointed Chairman of the Department of Surgery at Indiana University (I.U.) School of Medicine, the first pediatric surgeon in the USA so honored. He developed a world-class training program and was a role model for his trainees. He selflessly served the University and the children of Indiana for more than 40 years. His tenure was marked by developing new clinical programs and research facilities, including one of the largest transplant programs in the country, the center for surgical technology, providing high-quality clinical care and significantly growing the

Martin Kaefer mkaefer@iupui.edu

1 Indiana University School of Medicine, Pediatric Urology, Indianapolis, IN, USA
Department of Surgery from 22 to 70 faculty members. He was a member of the AOA.
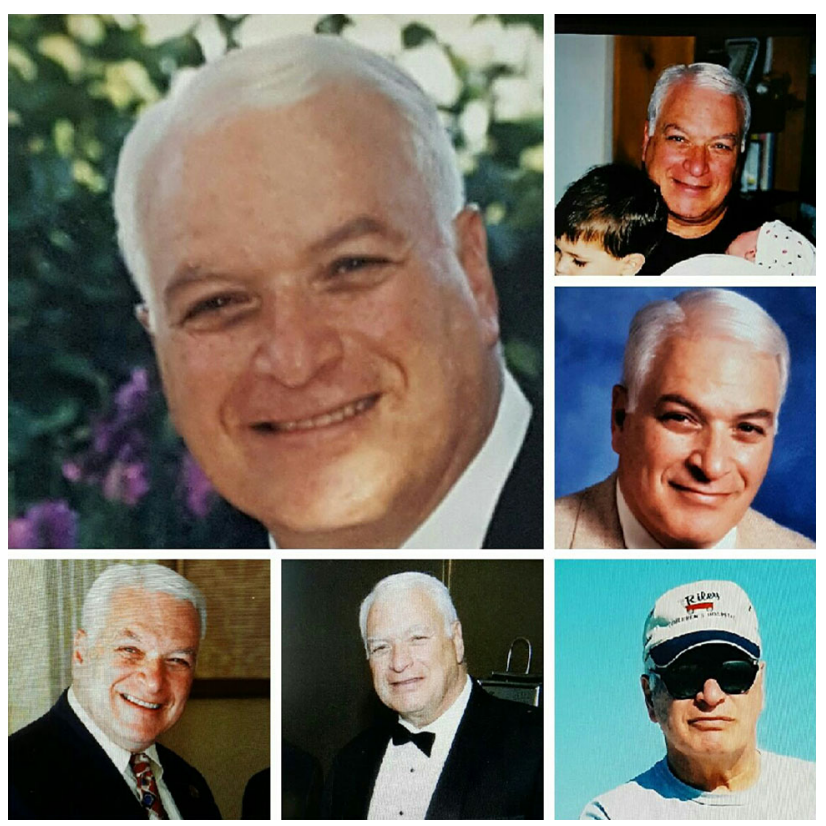

Dr. Grosfeld was recognized as an outstanding clinician, master surgeon, inspiring teacher, talented administrator, innovative scientific investigator, surgical leader and a staunch advocate for children. He won numerous teaching awards at I.U. including the prestigious President's Award, and The Glenn W. Irwin award for Distinguished Faculty services. He was extremely productive and published 491 scientific articles in peer-reviewed journals, 135 book chapters and nine textbooks. He was best known for his expertise in neonatal surgery, pediatric surgical oncology and surgical education. 
Dr. Grosfeld served as Secretary and Chairman of the Surgical Section of the American Academy of Pediatrics, President of the American Pediatric Surgical Association, President of the Halsted Society and was the only pediatric surgeon to serve as Chairman of the American Board of Surgery and also served as Vice-Chair of the Residency Review Committee. He served as President of both the Central Surgical Association and the Western Surgical Association. He served as President of the American Surgical Association, the only pediatric surgeon so honored, and as a Governor and member of the Advisory Councils for both General Surgery and Pediatric Surgery and other Committees of the American College of Surgeons, later becoming First Vice-President, and served as Council Member of the British Association of Pediatric Surgeons. He has been selected for Who's Who in America in five separate categories, and America's Best Doctors.

Dr. Grosfeld was influential in the development of the World Federation of Associations of Pediatric Surgeons (WOFAPS), serving as its first president for three years. Jay oversaw the establishment of its foundation and developed the Declaration of Pediatric Surgery, defining it internationally to provide the best care to children in all countries. He was honored with a lifetime achievement award in WOFAPS in 2013. He was awarded the Denis Browne Gold Medal by the British Association of Pediatric Surgeons in 1998, and was named Pediatric Surgeon of the Year at the University of Graz, Austria in 2000. In 2002, he received the William E. Ladd Medal from the American Academy of Pediatrics, the highest honor bestowed on a pediatric surgeon in the USA. In 2002 he also received the Sagamore of the Wabash Award from the late Governor of Indiana Frank O' Bannon for his outstanding service to the State. Dr. Grosfeld was awarded the Fritz Rehbein Medal from the European Pediatric Surgical Association in 2011. Dr. Grosfeld lectured extensively, both nationally and internationally and was elected an honorary member of 17 international surgical societies including an Honorary Fellowship in the Royal College of Surgeons of both England and Ireland, as well as the Royal College of Physicians and Surgeons of Glasgow. He was awarded the prestigious Solomon A. Berson Medical Alumni Achievement Award in Clinical Science from New York University, and the Arnold M. Salzberg Mentorship award from the AAP in 2012. Jay was Editor-in-Chief of the Journal of Pediatric Surgery, Founder and Editor of Seminars in Pediatric Surgery, and the Editor-in-Chief of the renowned two-volume textbook Pediatric Surgery. He was Co-editor of Surgery of Childhood Tumors. He was Founder and Chairman of the Board of Directors of the APSA Foundation. He received the APSA Distinguished Service Award in 2013.

In 1985, he set up the first children's surgical program for the ISS. He served as Secretary-Treasurer of the International Society of Surgery Foundation and was awarded its honorary life membership in 2013. He was the President and then Vice-President of the American Surgical Association Foundation. His international involvement began at the BAPS meeting in 1969 and spanned 47 years.

As staggering as these many accomplishments may be, it is equally important to look beyond the accolades of this great man. A simple listing of professional accomplishments is not adequate to convey his true strength of character.

Many have commented over the years on how they cannot fathom where he found so much energy to accomplish what he did for his profession. His life is even more noteworthy when one realizes that he only devoted a portion of his energy to his profession, the remainder being spent developing deeply personal relationships, especially with his family. These strong bonds sustained him through many challenges and brought him incredible joy. My father in law's greatest legacy was his family. He was happily married to his devoted wife Margie for 54 years and together they set a standard for a successful and close family life. He remains a source of strength and inspiration for his wife Margie; sister Claire Zucker; children, Alicia (Bruce) Thorne, Dalia (Jean-Philippe) Maheu, Janice (Martin) Kaefer, Jeffrey (Deborah) Grosfeld, and Mark Grosfeld; and his 17 grandchildren.

I personally was blessed to know this man in his many facets. He was the mentor I needed. As his student I found him to be a demanding teacher. Some may have even felt that he occasionally set the bar of expectation higher than one could reach. One thing is true, regardless of how much he asked of you, he always acted out of intent for improvement and inclusion. He was an example of excellence. You knew what to expect from Jay Grosfeld. He was fair and consistent.

I deeply admired the man. He was an example to my children that reinforced every positive value that you hope to pass on to the next generation. He was uncompromising in his integrity. He was funny and full of humor. I speak for many when I say that we will dearly miss his friendship and counsel. 